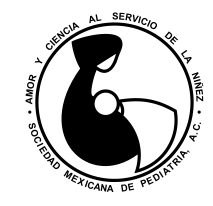

Revista Mexicana de
Vol. 86, No. 4 • Julio-Agosto 2019 pp 159-161

Recibido: 03/10/2018 Aceptado: 06/04/2019

dx.doi.org/10.35366/SP194G

\title{
Microcefalia asociada a síndrome de transfusión feto-fetal
}

\author{
Carlos Manuel Montaño-Pérez, ${ }^{1, *}$ Viviana Mendoza-Sánchez, ${ }^{1}$ Manuel Cazarez-Ortiz ${ }^{2}$ \\ ${ }^{1}$ Residente de $2^{\circ}$ año de Neonatología; ${ }^{2}$ Titular del curso de Neonatología. \\ Centro Médico Nacional 20 de Noviembre, ISSSTE, Ciudad de México
}

\begin{abstract}
RESUMEN
Se presenta el caso de una recién nacida con diagnóstico de microcefalia con antecedente de haber sido un embarazo gemelar monocorial, biamniótico, con muerte intrauterina del otro gemelo. Antes de hacer el diagnóstico de síndrome de transfusión feto-fetal se descartaron otras enfermedades asociadas mediante estudios de laboratorio y de imagen.
\end{abstract}

Palabras clave: Recién nacido, microcefalia, síndrome de transfusión feto-fetal, diagnóstico prenatal.

\section{INTRODUCCIÓN}

Los defectos intracraneales prenatales observados en el recién nacido son más frecuentes en embarazos gemelares, especialmente en los gemelos monocigóticos. ${ }^{1} \mathrm{El}$ síndrome de transfusión gemelo a gemelo (STFF) es la complicación más común del embarazo gemelar monocorial y ocurre hasta en el 15\% de este tipo de embarazos. ${ }^{2}$ El impacto en el gemelo superviviente se puede observar en varios niveles, llamando la atención las anomalías del sistema nervioso central (SNC) como quiste porencefálico, encefalopatía multiquística, hidrocefalia, microcefalia, hidranencefalia, necrosis del cerebelo y necrosis medular; todas, responsables de discapacidades psicomotoras. ${ }^{3}$

Las anastomosis vasculares placentarias en gestaciones monocoriales serían la causa de accidentes tromboembólicos que tienen al cerebro como el principal

\begin{abstract}
We present the case of a newborn with a diagnosis of microcephaly with a history of having been a monochorial, biamnotic twin pregnancy, with intrauterine death of the other twin. Before diagnosing fetal-fetal transfusion syndrome, other associated diseases were ruled out by laboratory and imaging studies.
\end{abstract}

Keywords: Newborn, microcephaly, fetal fetus transfusion syndrome, prenatal diagnosis.

órgano diana. En la mayoría de estos casos se encuentra el antecedente de feto muerto intra-útero. El daño estructural cerebral se produce por la transferencia feto-fetal de material tromboblástico, procedente del feto muerto. ${ }^{1}$

Los patrones de lesión cerebral en el gemelo superviviente varían de acuerdo con el momento de la muerte del otro gemelo y con el tipo de anastomosis circulatoria entre gemelos. ${ }^{4}$ Las publicaciones al respecto son escasas, por lo que se presenta un caso de microcefalia asociado a STFF.

\section{PRESENTACIÓN DEL CASO}

Recién nacida $(\mathrm{RN})$ con fecha de nacimiento el 22 de junio de 2018. Lugar de nacimiento: Centro Médico Nacional 20 de Noviembre, localizado en la Ciudad de México. Antecedentes heredofamiliares: madre de 34

\footnotetext{
* Correspondencia: CMMP, drcmontano@gmail.com

Conflicto de intereses: Los autores declaran que no tienen.

Citar como: Montaño-Pérez CM, Mendoza-Sánchez V, Cazarez-Ortiz M. Microcefalia asociada a síndrome de transfusión feto-fetal. Rev Mex Pediatr. 2019; 86(4):159-161.

[Microcephaly associated with feto-fetal transfusion syndrome]
} 
años, originaria y residente de la Ciudad de México, aparentemente sana. Grupo sanguíneo: O Rh positivo. Padre de 33 años, originario y residente de la Ciudad de México, sano. Antecedentes perinatales: gesta uno, control prenatal adecuado. Cervicovaginitis e infección de vías urinarias durante el tercer trimestre.

Se traslada a esta unidad debido a diagnóstico de embarazo gemelar monocorial biamniótico de 27.1 semanas de gestación y porque se detectó STFF estadio Quintero V. Al iniciar abordaje se confirmó diagnóstico mediante ultrasonido (USG), en el cual el reporte fue el siguiente: Feto A: circunferencia cefálica $24.2 \mathrm{~cm}$, ventriculomegalia bilateral moderada $(14 \mathrm{~mm})$, índice de pulsatilidad de arterias uterinas anormal, derrame pericárdico de $4 \mathrm{~mm}$. Feto B: ausencia de movimientos y actividad cardiaca.

Se decide interrupción del embarazo por cesárea debido a sangrado transvaginal. En el transoperatorio se detectó líquido amniótico fétido. Al momento del nacimiento la $\mathrm{RN}$ se encontraba no vigorosa con frecuencia cardiaca $<100$ latidos/minuto y con esfuerzo respiratorio irregular. Se administra un ciclo de ventilación con presión positiva, Apgar 7/8, Silverman Andersen 3. Peso: 2,330 gramos, talla: $47 \mathrm{~cm}$, perímetro cefálico: $27.9 \mathrm{~cm}$, perímetros torácico y abdominal: $30 \mathrm{~cm}$. Edad gestacional: 36.5 semanas por Capurro.

Se determinó que la $\mathrm{RN}$ tenía microcefalia dado que el perímetro cefálico se encontraba a $<4$ desviaciones estándar; también se observó que el tamaño de la fontanela anterior tenía una dimensión de $1 \times 1 \mathrm{~cm}$, y la fontanela posterior puntiforme, además de presentar sutura sagital cabalgada. A nivel neurológico se observó activa, sin movimientos anormales, con succión y deglución adecuada. El resto de la exploración física fue normal.
En sus primeras horas de vida extrauterina cursó con bradicardias sinusales de hasta 80 latidos/minuto, sin repercusión clínica. Por la dificultad respiratoria al nacer se utilizó oxígeno suplementario en fase I, éste fue suspendido a las 12 horas de vida. Se hizo diagnóstico de sepsis temprana, sin germen aislado, por lo cual se manejó con ampicilina y amikacina durante siete días.

Estudios de imagen. En el USG transfontanelar se reportó: imágenes hiperecoicas compatibles con probables calcificaciones. La tomografía de cráneo: atrofia cortical y subcortical, calcificaciones parenquimatosas. Imagen de resonancia magnética: disgenesia de cuerpo calloso, paquigiria, calcificaciones subcorticales y periventriculares, disminución de volumen corticosubcortical (Figuras 1 y 2).

Estudios de laboratorio: los anticuerpos séricos de madre y producto fueron negativos a Toxoplasma spp., rubéola, herpes, Epstein Barr y citomegalovirus. Inclusiones citoplasmáticas en orina y serología para ZIKA, negativo.

Se interconsulta al servicio de genética: no se integra síndrome específico.

Electroencefalograma: ondas delta difusas sugestivas de daño cortical, sin crisis convulsivas. Potenciales evocados auditivos y visuales: integridad de vía auditiva e inmadurez visual, con respuesta normal de retina.

Reporte histopatológico placentario: monocorial, biamniótica, con vellosidades de tercer trimestre, calcificaciones e infartos intervellosos, membranas con corioamnionitis crónica.

Con los resultados de todos estos estudios se integra el diagnóstico de microcefalia severa secundaria a síndrome de transfusión feto-fetal.

La paciente fue egresada para continuar seguimiento de neurodesarrollo y en programa de rehabilitación física.
Figura 1:

Resonancia magnética nuclear: atrofia cortical y subcortical, calcificaciones parenquimatosas.
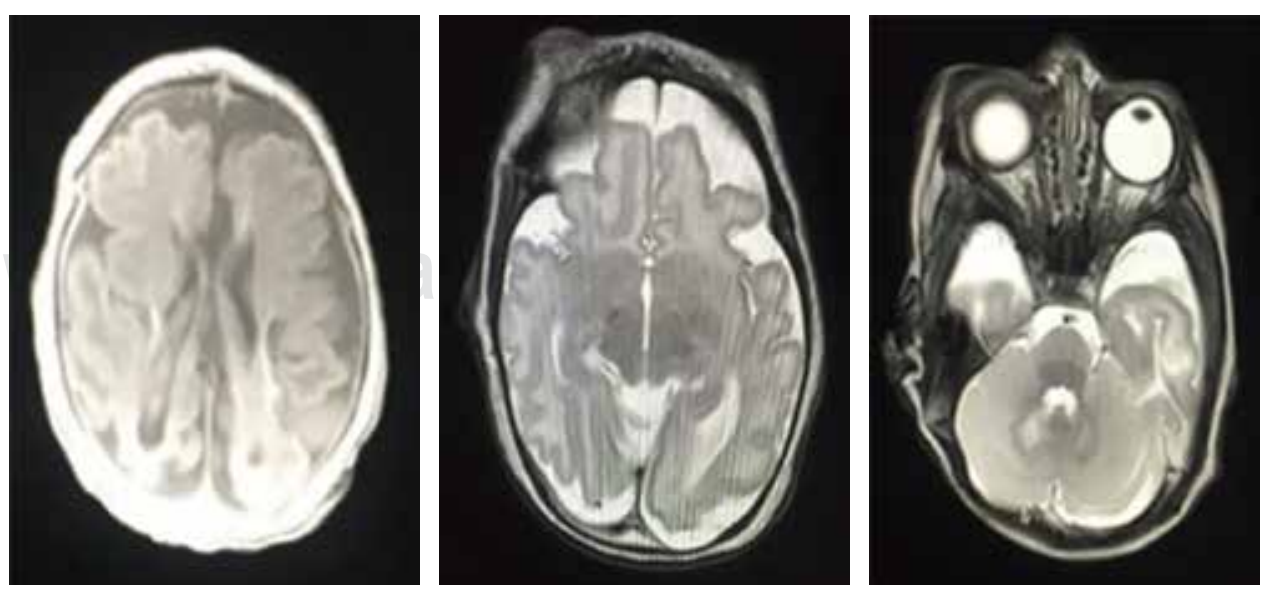

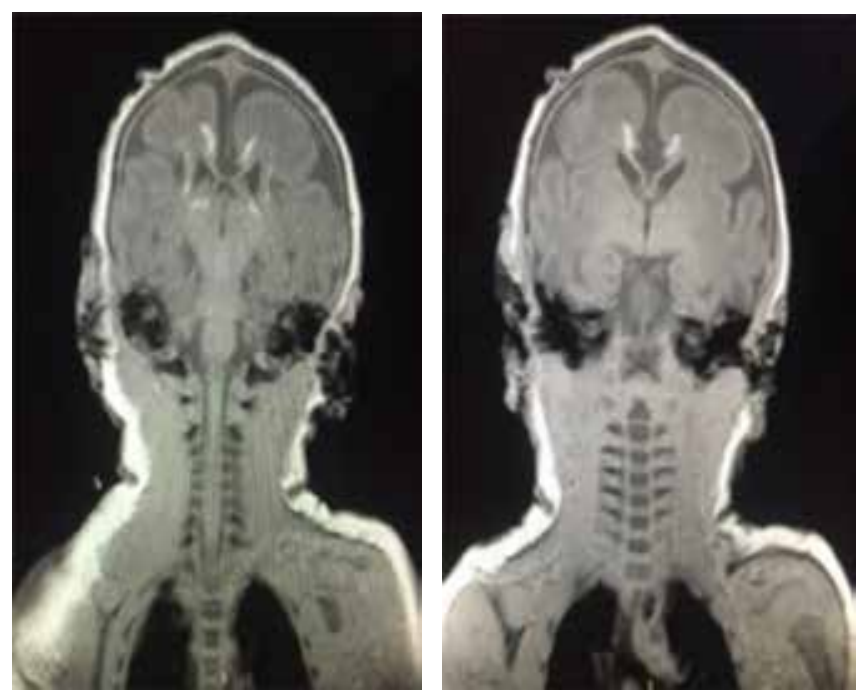

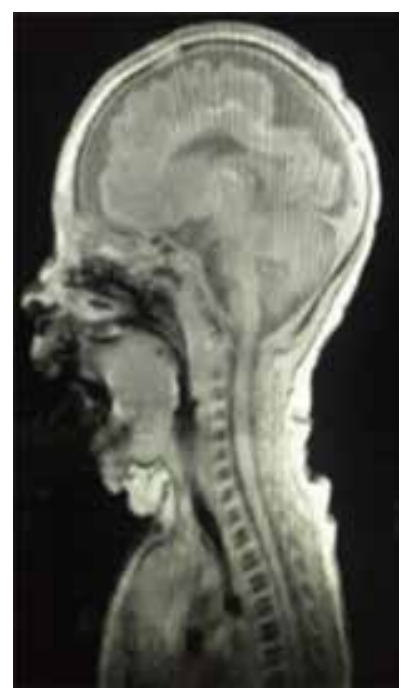

Figura 2:

Resonancia magnética nuclear: disgenesia de cuerpo calloso, paquigiria, calcificaciones subcorticales y periventriculares, disminución de volumen córticosubcortical.

\section{DISCUSIÓN}

La presencia de microcefalia en los $\mathrm{RN}$ plantea el diagnóstico diferencial entre las causas genéticas o adquiridas, lo cual no siempre resulta sencillo. La microcefalia congénita no genética obedece a agresiones durante la gestación, tales como disrupción vascular, tóxicos, infecciones y radiaciones. ${ }^{1}$

Es bien conocido que los gemelos monocigóticos presentan mayor incidencia de defectos estructurales que los dicigóticos o fetos únicos. Aunque la teoría más aceptada es que se trate de fenómenos tromboembólicos, también se han implicado episodios de hipotensión severa con hipoperfusión en la génesis del daño hipóxico-isquémico. ${ }^{1}$ Cuando existe el antecedente de un gemelo fallecido intra-útero debe hacerse un seguimiento ecográfico y clínico del gemelo superviviente, tanto prenatal como postnatal, para identificar este tipo de defectos y considerar el momento más oportuno para finalizar el embarazo ${ }^{1}$ como fue el caso de esta paciente cuyo gemelo falleció intra-útero.

En cuanto a la patogenia se ha sugerido que la inestabilidad de la presión arterial o de los episodios de hipotensión severa podrían ocasionar lesiones cerebrales en el gemelo receptor. En caso de muerte fetal la ocurrencia de lesiones en el sobreviviente es impredecible y aún no se ha propuesto una política uniforme.

A diferencia de la mayoría de los casos publicados, nuestra paciente no presentó afección neurológica grave, únicamente microcefalia. En estos pacientes, dependiendo de la severidad y del momento del accidente disruptivo, se podrían presentar distintos defec- tos cerebrales como porencefalia, ventriculomegalia, atrofia cerebral difusa e hidranencefalia, siendo la más frecuente la encefalomalacia multiquística. ${ }^{1} \mathrm{En}$ esta paciente, los estudios de imagen revelaron hallazgos similares a los reportados previamente: atrofia cerebral, ventriculomegalia, microcefalia. Larroche y colaboradores ${ }^{5}$ también informaron los mismos datos.

El diagnóstico etiológico de una microcefalia de origen prenatal supone un reto para el médico, lo cual incluye información para determinar el pronóstico neurológico, así como para brindar consejo genético. Se estima que en sólo $0.5 \%$ de las gestaciones gemelares monocoriales se produce daño cerebral. Por tanto, el riesgo de recurrencia es mínimo, ya que la probabilidad de una nueva gestación gemelar monocorial es muy baja.

\section{REFERENCIAS}

1. Lozano MF, Pisón JL, Faci AG, Moisés VR, Andrés MS, Tello AM. Microcefalia con atrofia cerebral severa en gestación gemelar monocorial. Anales españoles de pediatría. Publicación Oficial de la Asociación Española de Pediatría (AEP). 1999; 50(4): 405-407.

2. Cincotta RB, Gray PH, Phythian G, Rogers YM, Chan FY. Long term outcome of twin-twin transfusion syndrome. Arch Dis Child Fetal Neonatal Ed. 2000; 83(3): F171-F176.

3. Gaucherand P, Rudigoz RC, Piacenza JM. Monofetal death in multiple pregnancies: risks for the co-twin, risk factors and obstetrical management. Eur J Obstet Gynecol Reprod Biol. 1994; 55(2): 111-115.

4. Okumura A, Hayakawa F, Kato T, Tsuji T, Negoro T, Watanabe $\mathrm{K}$. Brain malformation of the surviving twin of intrauterine co-twin demise. J Child Neurol. 2007; 22(1): 85-88.

5. Larroche JC, Droulle P, Delezoide AL, Narcy F, Nessmann C. Brain damage in monozygous twins. Biol Neonatole. 1990; 57(5): 261-278. 